REVISTA DE DERECHO UNED, NÚM. 9, 2011

\title{
DELIMITACIÓN DE LA PROTECCIÓN CIVIL DEL DERECHO AL HONOR, A LA INTIMIDAD Y A LA PROPIA IMAGEN*
}

\author{
SONia CALAZa LÓPEZ \\ Profesora Titular de Derecho Procesal. UNED
}

Resumen: El proceso civil de tutela del derecho al honor, a la intimidad y a la imagen encuentra su fundamento en la protección de estos derechos fundamentales de naturaleza sustantiva garantizados en el artículo 18 de la Constitución Española (CE) y regulados por la LO 1/1982, de 5 de mayo, de protección civil del derecho al honor, a la intimidad personal y familiar y a la propia imagen (LOPH). Ahora bien, esta LOPH no acomete distinción alguna entre cada uno de estos derechos, de dónde podría inferirse que la tutela del derecho al honor comporta, al propio tiempo, la de la intimidad y la propia imagen. La realidad histórica nos muestra múltiples casos en los que, en efecto, se produce, en unidad o sucesión de actos, una quiebra conjunta de los tres derechos fundamentales mencionados, pero ello no resulta óbice para reconocer que, en otras ocasiones, la lesión del derecho individual o concretamente vulnerado incide, de manera directa y exclusiva, en el honor, en la intimidad o en la imagen, sin interferencia o, si se prefiere, injerencia recíproca alguna. En este estudio tratamos de acometer, sin ánimo exhaustivo, un estudio sobre cual sea el bien o interés jurídico específicamente protegido por cada uno de estos derechos.

Palabras clave: derecho al honor, derecho a la intimidad, derecho a la propia imagen.

* Este trabajo ha sido realizado en el marco del Proyecto de investigación titulado Stop Hate Crimes in Europe, bajo la dirección y coordinación de la Profesora Carmen Quesada Alcalá, Programa Justicia Penal, Dirección General de Justicia, Libertad y Seguridad de la Comisión Europea, con referencia JLS/2009/JPEN/AG. 
Abstract: The civil process of guardianship of the right to the honor, to the intimacy and to the image finds his foundation in the protection of these fundamental rights of substantive nature guaranteed in the article 18 of the Spanish Constitution (CE) and regulated by her 1/1982, of May 5, of civil protection of the right to the honor, to the personal and familiar intimacy and to the own image (LOPH). Now then, this LOPH does not attack any distinction between each of these rights, wherefrom there might be inferred that the guardianship of the right to the honor endures, to the own time, that of the intimacy and the own image. The historical reality shows us multiple cases in which, in effect, it takes place, in unit or succession of acts, a bankruptcy combines of three fundamental mentioned rights, but it does not turn out to be an obstacle to recognize that, in other occasions, the injury of the individual right or concretely damaged it affects, in a direct and exclusive way, in the honor, in the intimacy or in the image, without interference or, if it is preferred, reciprocal some interference. In this study we try to attack, without exhaustive spirit, a study on which it is the good or juridical interest specifically protected by each of these rights.

Key words: Right to the honor, right to the intimacy, right to the image.

Sumario: Introducción.-I. Delimitación de la protección civil del derecho al honor.-II. Delimitación de la protección civil del derecho a la intimidad.-III. Delimitación de la protección civil del derecho a la propia imagen.-IV. Bibliografía.

\section{INTRODUCCIÓN}

El proceso civil de tutela del derecho al honor, a la intimidad y a la imagen encuentra su fundamento en el amparo de estos derechos fundamentales de naturaleza sustantiva garantizados en el artículo 18 de la Constitución Española (CE) y regulados por la LO 1/1982, de 5 de mayo, de protección civil del derecho al honor, a la intimidad personal y familiar y a la propia imagen (LOPH).

Ahora bien, esta LO 1/1982, de 5 de mayo, de protección civil del derecho al honor, a la intimidad personal y familiar y a la propia imagen, no acomete distinción alguna entre cada uno de estos derechos, de dónde podría inferirse que la tutela del derecho al honor comporta, al propio tiempo, la de la intimidad y la de la propia imagen.

La realidad histórica nos muestra múltiples casos en los que, en 
efecto, se produce, en unidad o sucesión de actos, una quiebra conjunta de los tres derechos fundamentales mencionados, pero ello no resulta óbice para reconocer que, en otras ocasiones, la lesión del derecho individual o concretamente vulnerado incide, de manera directa y exclusiva, en el honor, en la intimidad o en la imagen, sin interferencia o, si se prefiere, injerencia recíproca alguna.

Es por ello por lo que hemos considerado la oportunidad y la conveniencia de acometer, sin ánimo exhaustivo, un estudio -eminentemente jurisprudencial ${ }^{1}$ - sobre cual sea el bien o interés jurídico específicamente protegido por cada uno de estos derechos.

Sin perjuicio de nuestra intención de acometer, en este estudio, una concreción de cual sea el contenido material de cada uno de estos tres derechos fundamentales (honor, intimidad e imagen), en el marco de su tutela procesal civil, no se nos oculta que la lesión de uno o varios de estos derechos suele producirse, de manera conjunta, debido a su "conflictiva relación jurídica» ${ }^{2}$, como consecuencia del libre ejercicio del derecho a la información y a la libertad de expresión o ideológica.

El artículo 20 de la CE reconoce y protege, en su apartado primero, de un lado -letra a)- el derecho a expresar y difundir libremente los pensamientos, ideas y opiniones mediante la palabra, el escrito o cualquier otro medio de reproducción, y, de otro -letra d)- el derecho a comunicar o recibir libremente información veraz por cualquier medio de difusión.

Estos derechos fundamentales -libertad de expresión, ideológica y de información- gozan de prioridad, prevalencia o preferencia frente a los anteriores -honor, intimidad e imagen- cuando concurran los requisitos jurisprudencialmente establecidos, puesto que si la prensa no es independiente y libre en una sociedad democrática, entonces, tal y como ha tenido ocasión de advertir nuestra procesalística mo-

${ }^{1}$ Los derechos fundamentales de la personalidad al honor, a la intimidad personal y familiar y a la propia imagen, garantizados en el número 1 del artículo 18 de la Constitución -tal y como ha reconocido el TS en sus sentencias de 13 de noviembre de 1989 y de 20 de julio de 2011-, «aunque tienen como base o soporte común el principio de la dignidad de la persona proclamado en el artículo 10 del mismo texto legal, son distintos, no pudiendo intercambiarse ni confundirse, pues cada uno da protección a un concreto y específico bien jurídico. Lo que no obsta a que una misma conducta pueda lesionar al mismo tiempo dos o los tres derechos referidos».

2 Vid., en este sentido, GimENo SENDRA, quién ha calificado, con su característica originalidad, de «conflictiva relación jurídica» a la permanente tensión existente entre ambos bloques de derechos constitucionales: honor, intimidad e imagen versus libertad ideológica, de información o de expresión, en «Derecho procesal civil. II. Los procesos especiales», Ed. Colex, $3^{\mathrm{a}}$ ed., Madrid, 2010, p. 368. 
derna $^{3}$, no se pueden consolidar los demás derechos fundamentales, se instala la corrupción en el gobierno y se obstaculiza seriamente el desarrollo de un país.

Así, la libertad de expresión quedará únicamente limitada por la eventual utilización de expresiones injuriosas, ajenas a las ideas expuestas o que resulten, a todas luces, innecesarias ${ }^{4}$.

La libertad de información quedará, asimismo, limitada por la eventual utilización de expresiones injuriosas, si bien en este último supuesto se requiere, al propio tiempo, la concurrencia simultánea de dos requisitos: en primer lugar, que el hecho relatado en la información sea veraz 5 ; y en segundo lugar, que la información, por la relevancia pública de su contenido ${ }^{6}$, se desenvuelva en el marco del interés general del asunto ${ }^{7}$, en lugar de servir de mera satisfacción para la curiosidad ajena ${ }^{8}$.

${ }^{3}$ Vid., por todos, Gimeno Sendra, V., «Libertad de expresión, honor e intimidad personal», Economist\&Jurist n ${ }^{\circ} 136$, diciembre-enero, 2010, p. 41.

4 SSTS 512/2000 de 11 de octubre de 2000; 481//2001 de 30 de enero de 2001; 913/2002 de 1 de octubre de 2002; 377/2003 de 8 de abril de 2003; 992/2003 de 24 de octubre de 2003; 1208/2003 de 11 de diciembre de 2003; 69/2004 de 13 de febrero de 2004; 718/2004 de 30 de junio de 2004; 634/2004 de 1 de julio de 2004; 649/2004 de 7 de julio de 2004; 796/2004 de 7 de julio de 2004; 810/2004, de 12 de junio de 2004 .

5 Conforme detalla la propia jurisprudencia -vid., entre otras, las SSTS de 17 de mayo de 1991; de 30 de octubre de 1993 y de 25 de marzo de1995- para una posible prevalencia del derecho a la libertad de expresión e información sobre el derecho al honor es necesario y preciso que se den una serie de presupuestos: en primer lugar que la información transmitida sea veraz, que esté referida a asuntos públicos que son de interés general por las materias que se tratan, e igualmente por las personas que se ven afectadas.

6 Vid., en este sentido, la STS de 29 de junio de 2011, dónde se señala que «la difusión de tales datos sobre su vida privada, era indiferente para el interés público, al carecer de relevancia pública, no afectando, por su objeto y su valor, al ámbito de lo público, sino que estaba destinada a suscitar o despertar, meramente, la curiosidad ajena, criterio que es mantenido por esta Sala, según el cual no cabe confundir el interés general y la relevancia pública (que legitiman la información por la necesidad de formación de una opinión pública sana, esencial para la vida democrática) con lo que son curiosidades, morbosidades o fisgoneos indiscretos en vidas ajenas (SSTS 105/1983, 159 y 168/1986, 20/1992 y de 15-7-1999).

7 Vid., entre otras, la STS de 10 de octubre de 2011, r. 386965, cuando afirma que «el conjunto de las declaraciones expuestas en el fundamento anterior son atentatorias del derecho al honor de la actora, por cuanto recogen afirmaciones que no resultan veraces, ni mínimamente contrastadas, no estando legitimada la intromisión en este derecho, porque los asuntos tratados, de forma vejatoria para la demandante, no son de relevancia pública, ni por razón de la materia tratada, ni por razón del personaje, que aunque sea de proyección pública no tiene por qué verse sometido, al agravio de revelar rumores sobre presuntas relaciones sentimentales con hombres y mujeres, incluso con un familiar, de forma difamatoria porque se alegó un interés económico, o supuestos embarazos y abortos».

8 SSTS 263/1994 de 28 de marzo; 820/1994 de 19 de septiembre; 1149/1994 de 20 
La libertad de expresión, reconocida en el artículo 20 CE, tiene, por lo demás, un campo de acción más amplio que la libertad de información ${ }^{9}$, porque en tanto esta se refiere a la narración de hechos, la de expresión alude a la emisión de juicios personales y subjetivos, creencias, pensamientos y opiniones. Comprende la crítica de la conducta de otro, aun cuando sea desabrida y pueda molestar, inquietar o disgustar a aquel contra quien se dirige ${ }^{10}$ pues así lo requieren el pluralismo, la tolerancia y el espíritu de apertura, sin los cuales no existe «sociedad democrática»"

\section{DELIMITACIÓN DE LA PROTECCIÓN CIVIL DEL DERECHO AL HONOR}

El TC se ha referido expresamente a la imposibilidad de encontrar una definición del derecho al honor en el ordenamiento jurídico ${ }^{12}$. Se trata de un concepto dependiente de las normas, valores e ideas sociales vigentes en cada momento ${ }^{13}$ que encaja, por tanto, sin dificultad en la categoría jurídica conocida con la denominación de «conceptos jurídicos indeterminados» ${ }^{14}$.

No obstante la imposibilidad de elaborar un concepto incontrovertible y de validez permanente sobre el derecho al honor ${ }^{15}$, ello no

de diciembre; 209/1995 de 6 de marzo; 259/1995 de 25 de marzo; 713/1995 de 10 de julio; 714/1995 de 15 de julio de 1995; 342/1995 de 6 de abril; 561/1996 de 5 de julio; 761/1997 de 31 de julio; 1075/1998 de 25 de noviembre; 966/99 de 20 de noviembre; 939/2000 de 18 de octubre; 247/2001 de 16 de marzo; 1054/2004 de 14 de noviembre; 1060/2003 de 4 de noviembre; 734/2003 de 10 de julio; 603/03 de 19 de junio; 1208/2003 de 11 de diciembre; 1153/2003 de 11 de diciembre.

${ }_{9}$ SSTC 104/1986, de 17 de julio y 139/2007, de 4 de junio.

10 SSTC 6/2000, de 17 de enero; 49/2001, de 26 de febrero; y 204/2001, de 15 de octubre.

11 SSTEDH de 23 de abril de 1992 (TEDH 1992, 1), Castells c. España, § 42, y de 29 de febrero de 2000 (TEDH 2000, 90), Fuentes Bobo c. España, § 43.

12 STC 223/92.

13 STC $185 / 89$.

14 STC 223/92.

15 Para un estudio específico sobre los derechos a la personalidad, se remite al lector a CABALLERo GEA, J. A., "Derecho al honor, a la intimidad personal y familiar y a la propia imagen. Calumnias e injurias», Ed. Dykinson, Madrid, 2004; CABEzuElo ARENAS, A. L., «Derecho a la intimidad», Ed. Tirant lo blanch, Valencia, 1998; CaLaza LóPEZ, S., «La tutela del derecho al honor, a la intimidad y a la propia imagen», en «Libro-homenaje al Prof. Torres del Moral», en prensa, 2012; CALlEJo CARRIóN, S., «El derecho al honor. El honor como objeto del proceso civil de amparo especial», Grupo difusión, Madrid, 2006; CONCEPCIÓN RODRíGUEZ, J. L., «Honor, intimidad e imagen. Un análisis jurisprudencial de la LO 1/1982», Ed. Bosch, Barcelona, 1996; GARCÍA GARCÍA, 
ha impedido al TC definirlo como el «derecho al respeto y al reconocimiento de la dignidad personal que se requiere para el libre desarrollo de la personalidad en la convivencia social, sin que pueda (su titular) ser escarnecido o humillado ante uno mismo o ante los demás» ${ }^{16}$.

El diccionario de la Real Academia Española ha declarado que el honor es la buena reputación (concepto utilizado por el Tratado de Roma) la cual, como la fama y aun la honra, consiste en la opinión que las gentes tienen de una persona -buena o positiva- si no va acompañada de adjetivo alguno. Si este es el anverso de la noción de honor -ha manifestado el $\mathrm{TC}^{17}$ - en el reverso están el deshonor, la deshonra o la difamación.

Con independencia de que el contenido del derecho al honor sea fluido y cambiante, esto es, dependiente de las normas, valores e ideas sociales vigentes en cada momento, puede decirse, con el TC, que el denominador común de todos los ataques o intromisiones ilegítimas en el ámbito de protección de este derecho es el desmerecimiento en la consideración propia o ajena como consecuencia de expresiones preferidas en descrédito o menosprecio de alguien, o que fueren tenidas en el concepto público por afrentosas ${ }^{18}$.

El artículo 7 de la LOPH establece, en los apartados tercero y séptimo, en desarrollo del artículo 18 de la $\mathrm{CE}$, que tendrán la consideración de intromisiones ilegítimas en el ámbito de protección del derecho al honor, de un lado, «la divulgación de hechos relativos a la vida privada de una persona o familia que afecten a su reputación y buen nombre, así como la revelación o publicación del contenido de cartas, memorias u otros escritos personales de carácter íntimo» y,

C., «El derecho a la intimidad y la dignidad en la doctrina del Tribunal Constitucional», Universidad de Murcia, 2003.; GIMENO SENDRA, V., «Libertad de expresión, honor e intimidad personal», Economist\&Jurist $n^{\circ}$ 136, diciembre-enero, 2010; GITRAMA GoNZÁLEZ, M., «Imagen (derecho a la propia)», Nueva enciclopedia jurídica, vol. XI, Ed. F. Seix, Barcelona, 1979; GRIMALT SERVERA, P., «La protección civil de los derechos al honor, a la intimidad y a la propia imagen», Ed. IUSTEL, Madrid, 2007; HERRÁN ORTIZ, A. I., «El derecho a la intimidad en la nueva Ley orgánica de protección de datos personales», Ed. Dykinson, Madrid, 2002; JAREÑo LEAL, A., «Intimidad e imagen: los límites de la protección penal», Ed. IUSTEL, Madrid, 2008; Morales PraTs, F., «La tutela penal de la intimidad: privacy e informática», Ed. Destino, Barcelona, 1984; Pascual Medrano, A., «El derecho fundamental a la propia imagen. Fundamento, contenido, titularidad y limites», Ed. Thomson-Aranzadi, Pamplona, 2003; RuIz Y Tomás, P., «Ensayo sobre el derecho a la propia imagen», Ed. Reus, Madrid, 1931.

16 STC 219/92.

17 STC 223/92.

18 STS de 20 de julio de 2011, r. 6137. 
de otro, «la divulgación de expresiones o hechos concernientes a una persona cuando la difame o la haga desmerecer en la consideración ajena».

Aún cuando la LOPH se refiere al desmerecimiento «en la consideración ajena», el TS ha tenido ocasión de señalar, en múltiples ocasiones $^{19}$, que el derecho al honor, en tanto que derecho a no ser escarnecido o humillado tiene, de un lado, una inminencia o trascendencia individual o interna cuando la expresión vejatoria suponga un desmerecimiento en la estimación propia de quién la sufre y, de otro, una dimensión o trascendencia social, cuando dicha expresión produzca un desmerecimiento en la consideración de quiénes conformen el entorno social o profesional de la persona agraviada ${ }^{20}$.

Así, pues, el TS ha conceptuado el derecho al honor, en numerosas resoluciones ${ }^{21}$, como un derecho derivado directamente de la «dignidad humana», que se refleja tanto en la consideración que de la misma tengan los demás, como en el sentimiento de consideración propia de esta persona; siendo por tanto dos aspectos a destacar uno el objetivo, y el otro el subjetivo, o lo que viene a ser lo mismo uno externo o social, y otro interno o personal ${ }^{22}$. La simple aportación de datos objetivos sobre la actividad personal y profesional en modo alguno conlleva ${ }^{23}$, sin embargo, una vulneración del derecho al honor.

${ }_{19}$ SSTS de 1 de julio de 1992; de 31 de julio de 1992; de 23 de diciembre de 1993, de 29 de junio de 2004 y de 10 de octubre de 2011, r. 386965.

${ }^{20}$ La STS de 23 de marzo de 1987 dice que este derecho fundamental se encuentra, en efecto, integrado por dos aspectos o actitudes íntimamente conexionados: el de la inmanencia, representado por la estimación que cada persona hace de sí misma, y el de la trascendencia o exterioridad integrada por el reconocimiento que los demás hacen de su dignidad. Este concepto que distingue la propia dignidad y el reconocimiento por los demás es mantenido por la de 26 de junio de 1987 que además, proclama el carácter de derecho fundamental, protegido constitucionalmente, del honor, y reiterado en las de 23 de febrero de 1989, de 12 de mayo de 1989, de 11 de junio de 1990, de 18 de noviembre de 1992, de 27 de enero de 1993 y de 23 de marzo de 1993. Otras sentencias vierten expresiones concretas para mantener la existencia de ataque al honor. Así ha sido muy reiterativa la frase de que es un ataque al honor «la atribución a una persona y la difusión de hechos que inexorablemente le hacen desmerecer público aprecio y reprochables a todas luces, sean cualquiera los usos sociales del momento (SSTS de 1-2-87, 19-2-88, 18-7-88, 11-6-90).

${ }^{21}$ Vid., entre otras, las SSTS de 11 de febrero de 2008 y de 10 de octubre de 2011.

${ }^{22} \mathrm{La}$ jurisprudencia ha puesto, en efecto, de manifiesto que tales derechos y en particular el derecho al honor se conceptúa como un derecho derivado directamente de la dignidad humana e implica la exigencia frente a los demás a no ser escarnecido ni humillado, lo que se producirá siempre a través de expresiones o hechos y actos atribuidos a esa persona que la hagan desmerecer de su propia estimación o de la estimación pública (entre otras STS de 23-02-1989).

${ }^{23}$ STS de 10 de octubre de 2011, r. 386965. 
El derecho al honor protege frente a atentados en la reputación personal entendida como la apreciación que los demás puedan tener de una persona, independientemente de sus deseos ${ }^{24}$, impidiendo la difusión de expresiones o mensajes insultantes, insidias infamantes o vejaciones que provoquen objetivamente el descrédito de aquella ${ }^{25}$. Así, pues, el «consentimiento», la «aquiescencia» o la «voluntad» de la persona afectada no exoneran, al titular de la intromisión ilegítima, de responder frente al perjuicio ocasionado como consecuencia de la inobservancia del irrenunciable derecho al honor.

Aunque el honor es un valor que debe referirse a personas físicas individualmente consideradas, el derecho a la propia estimación o al buen nombre o reputación en que consiste no es patrimonio exclusivo de las mismas ${ }^{26}$. A través de los fines de la persona jurídico-privada puede establecerse un ámbito de protección de su propia identidad en el sentido de protegerla para el desarrollo de sus fines y proteger las condiciones de ejercicio de la misma ${ }^{27}$. La persona jurídica puede así ver lesionado su derecho mediante la divulgación de hechos concernientes a su entidad, cuando la infame o la haga desmerecer en la consideración ajena.

El derecho al honor, según reiterada jurisprudencia ${ }^{28}$, se encuentra limitado por las libertades de expresión e información. La limitación del derecho al honor por la libertad de expresión e información tiene lugar cuando se produce un conflicto entre ambos derechos ${ }^{29}$, el cual debe ser resuelto mediante técnicas de ponderación constitucional, teniendo en cuenta las circunstancias del caso ${ }^{30}$.

${ }^{24}$ STC $14 / 2003$, de 28 de enero.

25 STC 216/2006, de 3 de julio.

26 STC 214/1991.

27 Según la jurisprudencia constitucional, el reconocimiento de derechos fundamentales de titularidad de las personas jurídicas necesita ser delimitado y concretado a la vista de cada derecho fundamental en atención a los fines de la persona jurídica, a la naturaleza del derecho considerado y a su ejercicio por aquella (SSTC 223/1992 y 76/1995).

${ }^{28}$ STS de 13 de julio de 2011, r. 5975.

${ }^{29}$ La jurisprudencia del TC sobre el conflicto entre los derechos a la libertad de información y de expresión, de un lado, y los derechos de la personalidad (honor, intimidad e imagen), de otro, ha sido cambiante, pudiendo distinguirse, conforme al minucioso estudio realizado por Gimeno SENDRA, V., tres fases o etapas: la del predominio de los derechos de la personalidad, la de la hegemonía de la libertad de información y la de la ponderación de dicho derecho con otros, asimismo, fundamentales, en «Libertad de expresión, honor e intimidad personal», cit., pp. 40 y ss.

30 Vid., las SSTS de 13 de enero de 1999, de 29 de julio de 2005, de 21 de julio de 2008, de 2 de septiembre de 2004, de 22 de julio de 2008, de 12 de noviembre de 2008, de 19 de septiembre de 2008, de 5 de febrero de 2009, de 19 de febrero de 2009, de 6 
Por «ponderación» se entiende, tras la constatación de la existencia de una colisión entre derechos, el examen de la intensidad y trascendencia con la que cada uno de ellos resulta afectado, con el fin de elaborar una regla que permita, dando preferencia a uno u otro, la resolución del caso mediante su subsunción en ella.

Cuando se trata de la libertad de información, la técnica de ponderación exige valorar, en primer término, el peso en abstracto de los respectivos derechos fundamentales que entran en colisión. Desde este punto de vista, la ponderación debe respetar la posición prevalente que ostenta el derecho a la libertad de información sobre el derecho al honor por resultar esta "prevalencia», tal y como hemos avanzado, esencial como garantía para la formación de una opinión pública libre, indispensable para el pluralismo político que exige el principio democrático ${ }^{31}$.

La protección constitucional de las libertades de información y de expresión alcanza un nivel máximo cuando la libertad es ejercitada por los profesionales de la información a través del vehículo institucionalizado de formación de la opinión pública que es la prensa, entendida en su más amplia acepción ${ }^{32}$. La técnica de "ponderación" exige valorar, en segundo término, el peso relativo de los respectivos derechos fundamentales que entran en colisión. Desde esta perspectiva, cabe destacar varias consideraciones:

En primer lugar, la ponderación debe tener en cuenta si la información tiene relevancia pública o interés general, se proyecta sobre personas que ejerzan un cargo público o una profesión de notoriedad o proyección pública o se trate de personas privadas en actividades de interés público ${ }^{33}$, pues entonces el peso de la libertad de información es más intenso, como establece el artículo 8.2.a) LPDH, en relación con el derecho a la propia imagen aplicando un principio que debe referirse también al derecho al honor. La "proyección pública» se reconoce en general por razones diversas ${ }^{34}$ : por la actividad política, por la profesión, por la relación con un importante suceso, por la trascendencia económica y por la relación social, entre otras circunstancias. En suma, la relevancia pública o interés general de la noticia

de julio de 2009, de 4 de junio de 2009, de 25 de octubre de 2010, de 15 de noviembre de 2010 y de 25 de enero de 2011.

31 STS 11 de marzo de 2009.

32 SSTC 105/1990, de 6 de junio y 29/2009, de 26 de enero.

33 STC 68/2008; SSTS 25 de octubre de 2000, de14 de marzo de 2003, de 19 de julio de 2004, de 6 de julio de 2009.

${ }^{34}$ STS de 17 de diciembre de 1997. 
constituye un requisito para que pueda hacerse valer la prevalencia del derecho a la libertad de información y de expresión cuando las noticias comunicadas o las expresiones proferidas redunden en descrédito del afectado.

En segundo lugar, la libertad de información, dado su objeto de puesta en conocimiento de hechos, cuando comporta la transmisión de noticias que redundan en descrédito de la persona, para que pueda prevalecer sobre el derecho al honor exige que la información cumpla el requisito de la veracidad, a diferencia de lo que ocurre con la libertad de expresión, que protege la emisión de opiniones. Por «veracidad» debe entenderse el resultado de una razonable diligencia por parte del informador para contrastar la noticia de acuerdo con pautas profesionales ajustándose a las circunstancias del caso, aun cuando la información, con el transcurso del tiempo, pueda ser desmentida o no resultar confirmada ${ }^{35}$. El requisito de la veracidad no empece que la total exactitud de la noticia pueda ser controvertida o se incurra en errores circunstanciales que no afecten a la esencia de lo informado ${ }^{36}$.

En tercer lugar, la transmisión de la noticia o reportaje no puede sobrepasar el fin informativo que se pretende dándole un carácter injurioso, denigrante o desproporcionado, porque, como viene reiterando el $\mathrm{TC}^{37}$, la $\mathrm{CE}$ no reconoce un hipotético derecho al insulto ${ }^{38}$.

En cuarto lugar, cuando la difusión de datos de carácter privado afecta no solo al personaje público, sino también a terceras personas, debe valorarse en qué medida la difusión de los datos relativos a estas está justificada por razón de su carácter accesorio en relación con el

35 SSTC $139 / 2007$ y $29 / 2009$.

36 SSTC 6/1988, de 21 de enero, 105/1990, de 6 de junio, 171/1990, de 12 de noviembre, 172/1990, de 12 de noviembre, 40/1992, de 30 de marzo, 232/1992, de 14 de diciembre, 240/1992, de 21 de diciembre, 15/1993, de 18 de enero, 178/1993, de 31 de mayo, 320/1994, de 28 de noviembre, 76/1995, de 22 de mayo, 6/1996, de 16 de enero, 28/1996, de 26 de febrero, 3/1997, de 13 de enero, 144/1998, de 30 de junio, 134/1999, de 15 de julio, 192/1999, de 25 de octubre, 53/2006, de 27 de febrero.

37 La protección del derecho al honor debe prevalecer frente a la libertad de expresión cuando se emplean frases y expresiones ultrajantes u ofensivas, sin relación con las ideas u opiniones que se expongan, y por tanto, innecesarias a este propósito, dado que el artículo 20.1 a) CE no reconoce un pretendido derecho al insulto, que sería, por lo demás, incompatible con la norma fundamental (SSTC 204/1997, de 25 de noviembre; 134/1999, de 15 de julio; 6/2000, de 17 de enero; 11/2000, de 17 de enero; 110/2000, de 5 de mayo; 297/2000, de 11 de diciembre; 49/2001, de 26 de febrero; 148/2001, de 15 de octubre; 127/2004, de 19 de julio; 198/2004, de 15 de noviembre y $39 / 2005$, de 28 de febrero).

38 SSTC 112/2000, 99/2002, 181/2006, 9/2007, 39/2007, 56/2008 de 14 de abril; SSTS 18 de febrero de 2009, 17 de junio de 2009. 
personaje público al que se refiere, la necesidad de su difusión para ofrecer la información de que se trate y la aceptación por el tercero de su relación con la persona afectada como personaje público.

La ponderación entre los derechos en conflicto debe efectuarse, por último, teniendo en cuenta si la publicación está justificada por los usos sociales. Debe valorarse la conducta previa del afectado por la difusión no consentida de la propia imagen como ocurre cuando la propia y previa conducta de aquél o las circunstancias en las que se encuentre inmerso justifiquen el descenso de las barreras de reserva para que prevalezca el interés ajeno o el público que puedan colisionar con él.

Constituye, finalmente, una doctrina consolidada del TS $^{39}$ la que advierte de que cuando la resolución del recurso de casación afecta a derechos fundamentales, como ocurre con el derecho al honor e intimidad y la libertad de expresión e información, este Tribunal no puede partir de una incondicional aceptación de las conclusiones probatorias obtenidas por las sentencias de instancia, sino que debe realizar, asumiendo una tarea de calificación jurídica, una valoración de los hechos en todos aquellos extremos relevantes para apreciar la posible infracción de los derechos fundamentales alegados ${ }^{40}$.

\section{DELIMITACIÓN DE LA PROTECCIÓN CIVIL DEL DERECHO A LA INTIMIDAD}

El derecho a la intimidad puede entenderse, con nuestra moderna doctrina procesal ${ }^{41}$, como el derecho a la soledad o a no ser molestado y a guardar reserva.

El fundamento del derecho a la intimidad y del derecho a la propia imagen ha de encontrarse en la intimidad, si bien uno y otro di-

${ }^{39}$ Este criterio se admite, entre otras resoluciones, por la STC 100/2009, de 27 de abril de 2009, la cual, anulando el ATS de 24 de mayo de 2005, declara, entre otros extremos, que «la falta de veracidad de la información (en el sentido que corresponde a este término, cuando se enjuicia la constitucionalidad del ejercicio del derecho de información) y el carácter vejatorio o no de las opiniones emitidas por el autor de los artículos periodísticos son cuestiones de estricto carácter jurídico, vinculadas a la ponderación sustantiva de los derechos fundamentales en conflicto».

40 Vid., entre otras, las SSTS de 7 de diciembre de 2005, de 27 de febrero de 2007, de 18 de julio de 2007, de 25 de febrero de 2008, de 2 de junio de 2009.

${ }^{41} \mathrm{Vid}$., en este sentido, Gimeno Sendra, V., quién, expone, al propio tiempo, con la finalidad de acometer un concepto más riguroso de lo que sea la «intimidad», de un lado, la teoría de las esferas: íntima, privada y pública, y de otro, la teoría del mosaico, en «Libertad de expresión, honor e intimidad personal», cit., pp. 45 y ss. 
fieren, tal y como hemos advertido en trabajos coetáneos a éste ${ }^{42}$, en su ámbito de actuación. Así, la intimidad personal y familiar se refiere, en esencia, a la privacidad, que habrá de ser respetada tanto por los ciudadanos, como, muy especialmente, por los poderes públicos. El derecho a la propia imagen, por el contrario, se refiere, en esencia, a la captación material o física de la imagen.

El derecho a la intimidad personal se configura como el derecho a la privacidad de un conjunto de actividades que vienen a configurar o delimitar un ámbito estrictamente personal, y que debe quedar vedado a la publicidad y divulgación al carecer de interés respecto de terceros. Por último el derecho a la propia imagen se define como aquél que impide la libre circulación, exposición y reproducción de la imagen personal sin autorización del afectado ${ }^{43}$.

El derecho a la intimidad personal implica la existencia de un ámbito propio y reservado frente a la acción y conocimiento de los demás, necesario según las pautas de nuestra cultura, para mantener una calidad mínima de la vida humana ${ }^{44}$.

Así el derecho a la intimidad es un derecho a impedir que los terceros -particulares o poderes públicos- decidan cuáles van a ser las lindes de nuestra vida privada, pudiendo cada persona reservarse un espacio resguardado de la curiosidad ajena, sea cual sea lo contenido en ese espacio ${ }^{45}$. Del precepto constitucional se deduce que el derecho a la intimidad garantiza al individuo un poder jurídico sobre la información relativa a su persona o a la de su familia, pudiendo imponer a los terceros su voluntad de no dar a conocer dicha información o prohibiendo su difusión no consenti-

42 Vid., Calaza LóPez, S., «La tutela del derecho al honor, a la intimidad y a la propia imagen», en «Libro-homenaje al Prof. Torres del Moral», en prensa, 2012.

43 Vid., por todas, la STS de 10 de octubre de 2011, r. 386965.

44 Vid., las SSTC 231/1988, 197/1991, 20/1992, 142/1993, 57/1994 y 207/1996.

45 Desde esta perspectiva de la dignidad de la persona, los detalles de la vida sentimental forman parte de ese ámbito propio y reservado de lo íntimo. En consecuencia, la vida sentimental y lo que acontezca en el seno de una relación matrimonial constituye una parcela de la esfera personal protegida por el derecho a la intimidad (STC 154/1999). Por tanto, las informaciones sobre relaciones afectivas ya tengan lugar dentro o fuera del matrimonio inciden en el ámbito garantizado en el artículo 18.1 CE (STC 21/2002). La vida sentimental de las personas ha sido considerada por la jurisprudencia una parte integrante y esencial de la esfera privada y, por tanto, de la intimidad, no solo desde un punto de vista objetivo sino también en su vertiente subjetiva, configurándose esta última como una expectativa de privacidad que el titular del derecho a la intimidad entiende que debe existir (SSTC 134/1999, de 15 de julio y 231/1998, de 2 de diciembre y SSTS de 8 de mayo de 1999 y de 22 de junio de 2004). 
$\mathrm{da}^{46}$. Y ello aunque la persona afectada haya difundido concretos aspectos de su vida privada, porque solo aquéllos que expresa y voluntariamente haya difundido pueden ser objeto de divulgación ${ }^{47}$.

El reconocimiento del derecho a la intimidad personal y familiar tiene por objeto, pues, garantizar al individuo un ámbito reservado de su vida, vinculado con el respeto de su dignidad como persona (artículo 10.1 CE), frente a la acción y el conocimiento de los demás, sean estos poderes públicos o simples particulares, de suerte que atribuye a su titular el poder de resguardar ese ámbito reservado, no solo personal sino también familiar ${ }^{48}$, frente a la divulgación del mismo por terceros y a la publicidad no querida ${ }^{49}$, evitando así las intromisiones arbitrarias en la vida privada, censuradas por el artículo 12 de la Declaración Universal de los Derechos Humanos.

En la solución del conflicto entre la libertad de información y el derecho a la intimidad personal, cabe destacar, conforme reiterada jurisprudencia del Tribunal Constitucional ${ }^{50}$, que el requisito de la veracidad de la información merece distinto tratamiento «según se trate del derecho al honor o del derecho a la intimidad, ya que, mientras la veracidad funciona, en principio, como causa legitimadora de las intromisiones en el honor, si se trata del derecho a la intimidad, actúa, en principio, en sentido diverso ${ }^{51}$. El criterio para determinar la legitimidad o ilegitimidad de las intromisiones en la intimidad de las personas, no es el de la veracidad, sino exclusivamente el de la «relevancia pública del hecho divulgado ${ }^{52}$, es decir, que su comunicación a la opinión pública, aun siendo verdadera, resulte ser necesaria en función del interés público del asunto sobre el que se informa ${ }^{53}$.

${ }^{46}$ SSTC 73/1982, 110/1984, 170/1987, 231/1998, 20/1992, 143/1994, 151/1997.

47 Vid., SAP de Madrid, de 30 de diciembre de 2005.

48 SSTC 231/1988, de 2 de diciembre y 197/1991, de 17 de octubre

49 SSTC 231/1988, de 2 de diciembre, 197/1991, de 17 de octubre y 115/2000, de 10 de mayo.

50 Vid., entre otras, la STC 115/2000.

51 En orden a los derechos de la intimidad personal y familiar resulta indiferente si la noticia fue veraz o no, pues la intimidad no es menos digna de respeto por el hecho de que resulten veraces las informaciones relativas «a la vida privada de una persona o familia que afecten a su reputación y buen nombre» (art. 7.3 de dicha Ley Orgánica), ya que, tratándose de la intimidad, la veracidad no es paliativo, sino presupuesto, en todo caso, de la lesión (SSTC 197/1991, de 17 octubre y 115/2000, de 10 mayo).

52 Vid. la STC 172/1990, de 12 de noviembre.

53 También el TS, en sus SSTS 12 y 18 de julio de 2004, así como de 29 de junio de 2011, destacan el «interés o relevancia pública» de los hechos divulgados como requisito para la legitimación de la información, al tiempo que recalcan la diferencia que existe entre lo que es interés histórico, científico o cultural relevante, de lo que es 
Aun cuando el artículo 18.1 CE garantiza el secreto sobre nuestra propia esfera de vida personal y, por tanto, veda que sean los terceros, particulares o poderes públicos quienes decidan cuáles son los contornos de nuestra vida privada ${ }^{54}$, este derecho fundamental no es ilimitado como ninguno lo es ${ }^{55}$. El ejercicio de este derecho, es decir, el secreto sobre la propia esfera personal queda supeditado al ejercicio que haga el poseedor del mismo de él ${ }^{56}$. La ruptura de la esfera de la intimidad poniendo en conocimiento de terceros datos que en principio podrían estar incursos en el mismo, sólo puede ser realizada por el sujeto, pero una vez que esto ha sucedido, ya no existe tal esfera ${ }^{57}$.

\section{DELIMITACIÓN DE LA PROTECCIÓN CIVIL DEL DERECHO A LA PROPIA IMAGEN}

El TC caracteriza el derecho a la propia imagen ${ }^{58}$ como «un derecho de la personalidad, derivado de la dignidad humana y dirigido a proteger la dimensión moral de las personas, que atribuye a su titular un derecho a determinar la información gráfica generada por sus rasgos físicos personales que pueden tener difusión pública» y a «impedir la obtención, reproducción o publicación de la propia imagen por parte de un tercero no autorizado, sea cual sea la finalidad informativa, comercial, científica, cultural, etc.- perseguida por quien la capta o difunde».

El derecho a la propia imagen se halla protegido en el artículo 18.1 CE y desarrollado en la LPDH, cuyo artículo 7.5 considera «intromisión ilegítima», la captación, reproducción o publicación por fo-

la simple curiosidad humana por conocer la intimidad de otros o ánimo de lucro por quien obtiene o divulga la información; En el mismo sentido la STEDH de 24 de junio de 2004, acentúa la importancia del interés o relevancia de la información como principio de su legitimación.

54 SSTC 83/2002, de 22 de abril y 99/2002 de 6 de mayo.

55 SSTC 159/1986, de 16 de diciembre y 297/2000 de 11 de diciembre.

${ }^{56}$ La ponderación entre los derechos en conflicto debe efectuarse teniendo en cuenta si la publicación de los datos de la vida privada está justificada por los usos sociales, o hay base para sostener que el afectado adoptó pautas de comportamiento en relación con su ámbito íntimo que permita entender que, con sus propios actos, lo despojó total o parcialmente del carácter privado o doméstico (STS de 6 de noviembre de 2003).

57 Quien divulgue aspectos de su vida privada debe soportar el conocimiento e investigación o seguimiento de los aspectos divulgados y la crítica de los mismos (STC de 27 de abril de 2010).

58 Vid., SSTC 231/1988; 99/1994; 117/1994; 81/2001; 139/2001; 156/2001; 83/2002; $14 / 2003$. 
tografía, filme o cualquier otro procedimiento, de la imagen de una persona en lugares o momentos de su vida privada o fuera de ellos, salvo los casos previstos en el artículo 8.2 LPDH. El ámbito propio de protección del derecho a la propia imagen es la defensa frente a los usos no consentidos de la representación pública de la persona que no encuentren amparo en ningún otro derecho fundamental ${ }^{59}$, muy destacadamente frente a la utilización de la imagen con fines puramente lucrativos a la que alude el artículo 7. 6 de la LO 1/1982 de Protección Civil del Derecho al Honor, a la Intimidad Personal y Familiar y a la Propia Imagen.

El contenido positivo del derecho a la propia imagen delimita el alcance de la libertad de expresión y del mismo modo este derecho se encuentra, a su vez, limitado por otros derechos y bienes constitucionales, en particular, por el derecho a la comunicación de información y a las libertades de expresión y creación artística ${ }^{60}$.

La prevalencia o prioridad del derecho a la información y expresión sobre el derecho a la imagen es mayor que sobre el derecho al honor y a la intimidad personal y familiar, por cuanto con carácter general, en los casos de fotografías difundidas públicamente el canon de relevancia que permite la afectación sobre el derecho a la propia imagen ha de ser necesariamente más tenue que el que faculte a una intromisión en los derechos al honor o la intimidad, en la medida en que es también menor la consecuencia lesiva sobre la dignidad que tiene en sí misma la mera reproducción gráfica de la representación externa de una persona ${ }^{61}$.

Lo especifico del derecho a la imagen, frente al derecho a la intimidad y el derecho al honor, tal y como matiza el $\mathrm{TS}^{62}$, es la protección frente a las reproducciones de la misma que, afectando a la esfera personal de su titular, no lesionan su buen nombre ni dan a conocer su vida íntima. El derecho a la propia imagen pretende salvaguardar un ámbito propio y reservado, aunque no íntimo, frente a la acción y conocimiento de los demás; un ámbito necesario para poder decidir libremente el desarrollo de la propia personalidad y, en definitiva, un ámbito necesario según las pautas de nuestra cultura para mantener una calidad mínima de vida humana.

Ese bien jurídico se salvaguarda reconociendo la facultad de evitar la difusión incondicionada de su aspecto físico, ya que constituye el

\footnotetext{
59 STS de 20 de julio de 2011, r. 6138.

60 SSTC 81/2001, de 26 de marzo y 139/2001, de 18 de junio.

${ }^{61}$ ATC 176/2007, de 1 de marzo.

62 Vid., la STS de 29 de junio de 2011, r. 5844.
} 
primer elemento configurador de la esfera personal de todo individuo, en cuanto instrumento básico de identificación y proyección exterior y factor imprescindible para su propio reconocimiento como sujeto individual ${ }^{63}$, por la propia voluntad del titular del derecho le corresponde decidir si permite o no la captación o difusión de su imagen por un tercero.

La aplicación del artículo 8.2.a) LPDH, como causa de justificación de una intromisión en la propia imagen, requiere, por lo demás, la concurrencia de los siguientes requisitos:

$1^{\circ}$. Que se trate de la captación, reproducción o publicación de una imagen.

$2^{\circ}$. Que la imagen reproducida sea la de un cargo público o una persona que ejerza una profesión de notoriedad o proyección pública.

$3^{\circ}$. Que la imagen sea captada durante un acto público o en un lugar abierto al público. En este caso no se incluirá en el artículo 8.2.a) LPDH aquellos en que la persona está en un lugar público, pero en un momento de su vida privada. La aplicación del artículo 8.2.a) LPDH, se circunscribe, pues, a los actos, situaciones, a los hechos, relacionados con la condición del cargo público o de la profesión de notoriedad o proyección pública que justifica tal precepto.

$4^{\circ}$ Que el uso de la imagen responda a una exigencia pública de información.

\section{BIBLIOGRAFÍA}

CABALlERo Gea, J. A., «Derecho al honor, a la intimidad personal y familiar y a la propia imagen. Calumnias e injurias», Ed. Dykinson, Madrid, 2004.

Cabezuelo Arenas, A. L., «Derecho a la intimidad», Ed. Tirant lo blanch, Valencia, 1998.

CALAZA LóPEZ, S., «La tutela del derecho al honor, a la intimidad y a la propia imagen», en «Libro-homenaje al Prof. Torres del Moral», en prensa, 2012.

${ }^{63}$ Vid., SSTC 231/1988, de 2 de diciembre; 99/1994, de 11 de abril; 81/2001, de 26 de marzo; 139/2001, de 18 de junio; 156/2001, de 2 de junio; 83/2002, de 22 de abril. 
Callejo Carrión, S., «El derecho al honor. El honor como objeto del proceso civil de amparo especial», Grupo difusión, Madrid, 2006.

CONCEPCIÓN RodRíGUEZ, J. L., «Honor, intimidad e imagen. Un análisis jurisprudencial de la LO 1/1982», Ed. Bosch, Barcelona, 1996.

García García, C., «El derecho a la intimidad y la dignidad en la doctrina del Tribunal Constitucional», Universidad de Murcia, 2003.

GIMENO SENDRA, V.,

— «Introducción al Derecho Procesal», Ed. Colex, Madrid, 2010.

— «Derecho Procesal Civil», II. Procesos especiales, Ed. Colex, $3^{\text {a }}$ ed., Madrid, 2010.

- «Libertad de expresión, honor e intimidad personal», Economist\&Jurist $\mathrm{n}^{\circ}$ 136, diciembre-enero, 2010.

Gitrama GonZÁlez, M., «Imagen (derecho a la propia)», Nueva enciclopedia jurídica, vol. XI, Ed. F. Seix, Barcelona, 1979.

Grimalt SeRVERA, P., «La protección civil de los derechos al honor, a la intimidad y a la propia imagen», Ed. IUSTEL, Madrid, 2007.

HerRán OrTIZ, A. I., «El derecho a la intimidad en la nueva Ley orgánica de protección de datos personales», Ed. Dykinson, Madrid, 2002.

JAREÑo LEAL, A., «Intimidad e imagen: los límites de la protección penal», Ed. IUSTEL, Madrid, 2008.

Morales Prats, F., «La tutela penal de la intimidad: privacy e informática», Ed. Destino, Barcelona, 1984.

Pascual Medrano, A., «El derecho fundamental a la propia imagen. Fundamento, contenido, titularidad y limites», Ed. ThomsonAranzadi, Pamplona, 2003.

RuIz Y Tomás, P., «Ensayo sobre el derecho a la propia imagen», Ed. Reus, Madrid, 1931. 
